\title{
LAND SUBSIDENCE MONITORING USING PS-InSAR TECHNIQUE FOR L-BAND SAR DATA
}

\author{
(Shailaja Thapa $^{a^{*}}$, R. S. Chatterjee ${ }^{\mathrm{a}}$, K. B. Singh ${ }^{\mathrm{b}}$, Dheeraj Kumar ${ }^{\mathrm{c}}$ ) \\ ${ }^{\text {a } I n d i a n ~ I n s t i t u t e ~ o f ~ R e m o t e ~ S e n s i n g, ~ D e h r a d u n ~} 248$ 001, India- (shailaja, rschatterjee,) @iirs. gov. in \\ ${ }^{\mathrm{b}}$ Central Institute of Mining and Fuel Research (kbsingh@yahoo.com) \\ ${ }^{\mathrm{c}}$ Indian School of Mines, Dhanbad 826004 (dheeraj@dkumar.org)
}

Commission VII, WG VII/2

KEY WORDS: Differential Interferometric synthetic (D-InSAR), Persistent Scatterer Interferometry, Levelling, Anthropogenic targets

\begin{abstract}
:
Differential SAR-Interferometry (D-InSAR) is one of the potential source to measure land surface motion induced due to underground coal mining. However, this technique has many limitation such as atmospheric in homogeneities, spatial de-correlation, and temporal decorrelation. Persistent Scatterer Interferometry synthetic aperture radar (PS-InSAR) belongs to a family of time series InSAR technique, which utilizes the properties of some of the stable natural and anthropogenic targets which remain coherent over long time period. In this study PS-InSAR technique has been used to monitor land subsidence over selected location of Jharia Coal field which has been correlated with the ground levelling measurement. This time series deformation observed using PS InSAR helped us to understand the nature of the ground surface deformation due to underground mining activity
\end{abstract}

\section{INTRODUCTION}

In India, Jharia Coal field covers the area of about 456 sq.km, situated $260 \mathrm{~km}$ northwest of Calcutta in the heart of Damodar valley. Jharia has witness intensive effort of exploitation since 1894 till nationalization of coal in 1972 due to unscientific techniques of mining. As a result, land subsidence phenomena has been seen in many places. Different types of subsidence phenomena can take place over the coal mining area:

1) Continuous Subsidence-Involves formation of gentle depression over broad area. This type of subsidence is associated with thin, horizontal or lateral dipping ore bodies is overlaid by weak and non-brittle strata, mostly seen in the case of long wall mining.

2) Discontinuous Subsidence- It is characterized by large surface displacement over limited surface area. Such as

a).Sink hole -This type of subsidence is very abrupt seen mostly in case of Room and Pillar mining,

b).Pillar Collapse-Seen in case of abandoned mining.

All the above mentioned subsidence phenomena in coal mining results in to severe damage of buildings, infrastructure, economy loss.

Ground based techniques like GPS and Levelling can measure lands subsidence phenomena up to $\mathrm{cm}$ to $\mathrm{mm}$ level precision. GPS can give all the three component of land subsidence with highest temporal resolution for a point locations. However, Point wise measurement of GPS reading does not provide required spatial density to identify the occurrence and magnitude of local- small scale land subsidence phenomena (Sharav, 2003). The Ground based conventional techniques are costly, time consuming, requires man power. InSAR has unique advantage as it can measure land subsidence in the absence of man power over large contiguous area with centimetric accuracy.

* Corresponding author. (email: shailaja @iirs.gov.in)
However, In most of all interferogram there exist some area which experience decorrelation due to change in scattering properties of surface scatterer with time, change in sensor geometry and due to variation in intervening atmospheric properties.

PS-InSAR is one of the multi time Interferometric technique which addresses both temporal and spatial decorrelation and atmospheric in homogeneities (Hernandez et al., 2014). In the present study PS-InSAR analysis has been performed over ALOS -1 data for Jharia Coal field. A specific focus is set on Jharia area, where subsidence has been identified using PSInSAR technique for a small test site, for validation levelling and conventional InSAR measurement has been used.

\section{RESEARCH AREA AND ACQUIRED DATASET}

\subsection{Research Area}

The research area is situated in Jharia Coal field, Jharkhand, Dhanbad, India. This is the only storehouse of prime coking coal in the country, which has a history of mining since 1894 also population wise it is one of the densely populated coal field in the world.

It is one of the oldest and chief coal field in India. Jharia and it's near around area are considered to have undulating and rolling topography, having slope towards east -south -east. The elevation of this area ranges from $240 \mathrm{~m}$ in the west to $140 \mathrm{~m}$ in the south east (Kumar. et al., 2012).During nationalization period all 398 mines (184 non- coking and 214 coking) were distributed under the management of Bharat Coking Coal Limited (BCCL), out of which six mine were authorized under the management of Tata Iron and Steel Company (TISCO) and two under Indian Iron and Steel Company (IISCO)(Singh. et al., 2010). In this area coal mining is the major occupation and it gives employment to 100,000 people which is the $10 \%$ of the total population of the area. Out of the total reserves of coal only $25 \%$ of coal have been extracted or consumed by coal fire 
since inception of the mining. The remaining $75 \%$ of coal is still remaining.

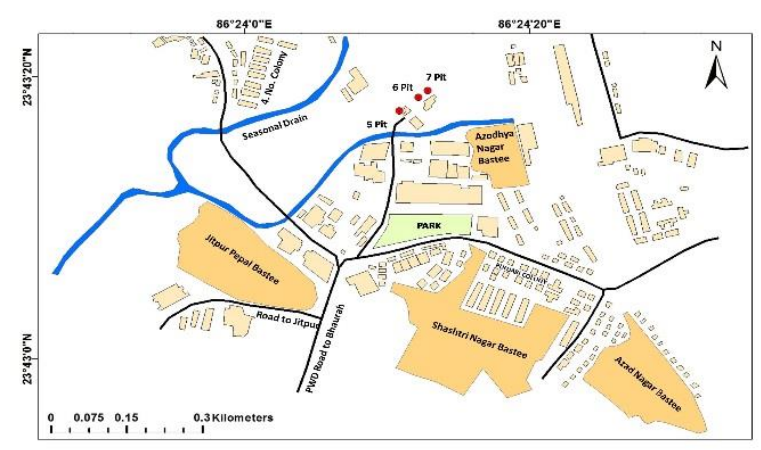

Figure 1. Surface plan map derived from TATA colliery

\subsection{SAR Data Used}

SAR Sensors are capable of acquire data irrespective of any weather condition, at any time of the day due to its own source of illumination but there number is strongly limited by the orbital parameters, climatic season and daily weather phenomena. One of the most important criteria to detect land subsidence using SAR Interferometry is selection of most accurate SAR scenes so that the selected pair only deciphers the surface change. A stack of 10 ALOS-1 pair were used from January 30, 2007, to December, 12, 2010 with perpendicular baseline not exceeding $2100 \mathrm{~m}$. The ALOS data were taken along ascending orbit. A digital elevation model (DEM) proposed by Shuttle radar topographic mission of 90 meter resolution were used as source of external DEM to eradicate the effect of topographic effect from the differential interferogram.

\section{PS IDENTIFCATION: AN ADAPTIVE METHODOLOGY}

As discussed above the main aim of the work is to identify phase stable point scatterer from the number of SAR pairs used. The work flow for the discussed study is given as follows:

1) Standard Interferometric process.

2) SAR data co registration

3) Geo-coding

4) Flattening and

5) Topographic

6) Phase subtraction.

In short PS -processing includes following steps:

1. Master image selection,

2. SAR data co- registration,

3. reflectivity map generation

4. amplitude stability index map,

5. persistent scatterer candidate selection (PSC),

6. PS point selection,

7. multi-image sparse grid phase unwrapping,

8. atmospheric phase screen estimation

9. removal and PS phased reading

10. Displacement estimation.

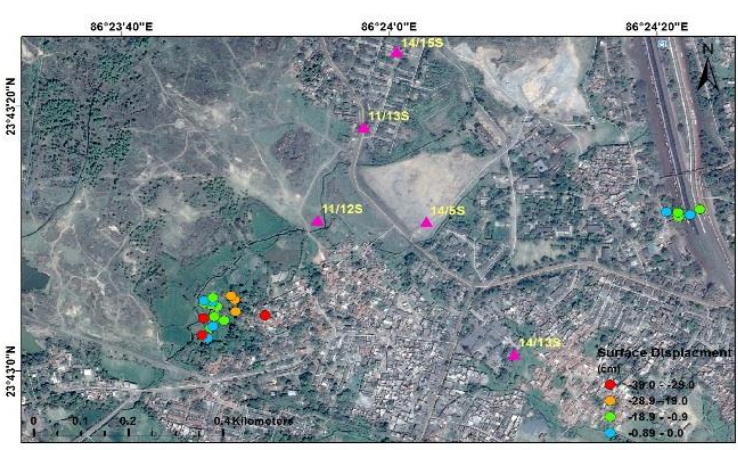

Figure 2. Surface Displacement map obtained using PS-InSAR Technique, Levelling site are marked with pink triangle showing corresponding seam number

\section{RESULTSANALYSIS AND DISCUSSION}

To investigate the proposed PS-InSAR techniques for the identification of subsidence zone due to underground mining activities in one of the Jharia test site, ALOS 10 scenes from 2007 to 2010 have been processed. All ALOS scene were acquired in ascending nodes. For the restriction of APS model, we have selected eastern part on the Jharia Coal field covering area of $4.9253 \mathrm{Sq}$. Km. In PS-InSAR are processing workflow nine filtered interferogram were generated. In PS-InSAR processing step for the selection of appropriate PS candidate different selection criteria were experimented. The amplitude stability index plus spatial coherence were used and fixed to 0.78 for the study area. Total psc were selected using further processing in the software LOS velocity map and cumulative displacement map were generated for the time period. Finally all the output were geocoded to validate with the levelling data.

\subsection{PS InSAR integration with levelling}

The subsidence map obtained from PS-InSAR method were correlated with levelling data acquired from Central Institute of Mining and Fuel Research (CMIFR), it has been observed that for the same area the levelling value shows good agreement with the PS- InSAR result. Levelling data of Jamadoba $6 / 7$ colliery gives following value:

\begin{tabular}{|l|l|l|l|}
\hline S.No & Seam Name & Subsidence $(\mathrm{Cm})$ & Year \\
\hline 1 & XIV / 13 S & 8.1 & $2006-2010$ \\
\hline 2 & XI / 12 S & 10 & $2006-2010$ \\
\hline 3 & XIV /5S & 0.6 & $2006-2010$ \\
\hline 4 & XIV /15S & 30 & $2006-2010$ \\
\hline
\end{tabular}

Table 1. Levelling Subsidence values from 2006-2010 for the different seam obtained from Central Institute of Mining and Fuel Research.

PS-InSAR value is also ranging from -0.89 to $39.04 \mathrm{~cm}$ which, is little bit high from the value obtained from levelling data. 


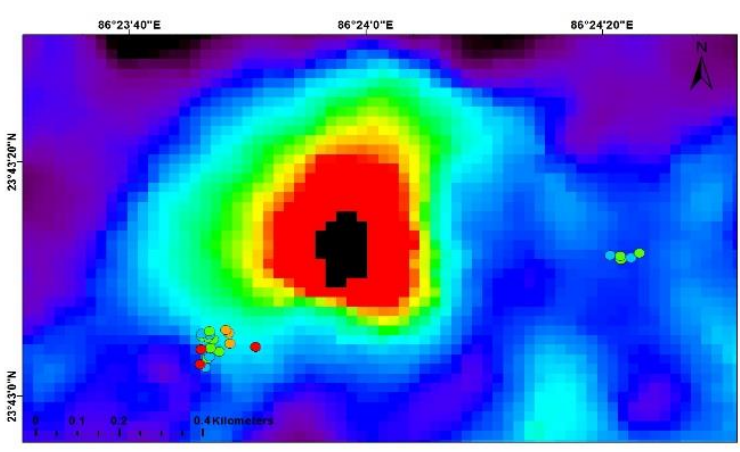

Figure 3. The fringe obtained from D-InSAR overlaid by PSInSAR result

\subsection{PS InSAR integration with D-InSAR Result}

Also, we have tried to compare the results of D-InSAR with PSInSAR result. It has been observed that for the same test site the subsidence rate obtained from D-InSAR processing is coming very close to the PS-InSAR displacement rate. The value obtained for Jamadoba Test site using D-InSAR is coming value of $39.04 \mathrm{~cm} / \mathrm{yr}$ (R. S. Chatterjee et al., 2015).

\section{CONCLUSION}

PS-InSAR is an advanced Interferometric tool, which gives surface deformation history, but the only limiting factor is availability of data. This is very good technique to understand and delineate surface deformation dynamics using large data set. It has been seen from this study that ten scenes of ALOS PALSAR also gives good agreement with the ground based and D-InSAR result. Increasing the number of Data pair will give more close and appropriate results for the surface deformation studies.

\section{ACKNOWLEDGEMENTS (OPTIONAL)}

This work is supported by Dr. A. Senthil Kumar, Director, Indian Institute of Remote Sensing, Dehradun, Dr. Amalendu Sinha, Director, Central Institute of Mining \& Fuel Research, Dhanbad. The authors sincerely thank and acknowledge the help and services provided by Mr. S.N. Rajak of Central Institute of Mining \& Fuel Research, Dhanbad.

The authors convey sincere thanks to the staff and officials of the mining agencies namely, Bharat Coking Coal Ltd, Tata Steel, and Steel Authority of India Ltd., Dhanbad for their help and cooperation during field survey and ground data collection.

\section{REFERENCES}

Hernandez, N. D., Madrigal, D., Exposito, J. L., Antonio, X., 2014. Multi-Temporal Analysis of Land Subsidence in Toluca Valley (Mexico) through a combination of Persistent Scatterer Interferometry (PSI) and Historical Piezo metric Data, Advances in Remote Sensing, 3, 49-60.

Kumar, P., Kumar, D., Mandal, V. V., Pandey, P. C.., Rani, M., Tomar, Vandana, 2012. Settlement Risk Zone Recognition Using High Resolution Satellite Data in Jharia Coal Field, Dhanbad, India, Life Science Journal ; 9(1S), ISSN :10978135).
Chatterjee, R. S., Thapa, Shailaja., Singh, K. B., Varunkumar, G., Raju, E.V. R., 2015. Detecting, mapping and monitoring of Land Subsidence in Jharia Coalfield, Jharkhand, India by spaceborne differential interferometric SAR, GPS and precision levelling techniques. Journal of Earth system science 124, No 6, pp. 1359-376

Sharav, A., 2003. Differential SAR Interferometry for Crustal Deformation Study, M.Sc., International Institute for GeoInformation and Earth Observation, the Netherlands.

Singh, G., Jain, M.K.,S Paul, B., Gupta, R.D., Raju, E.V.R., 2010. Clusterization of mines for Obtaining Comprehensive Environmental Clearance: A Case Study of BCCL Lease Hold Areas, Journal of Indian School of Mines, Special Volume 2010, pp. 13-20. 